\title{
Caracterização morfológica e molecular de acessos de melancia
}

\author{
Maria Luciene da Silva ${ }^{1}$; Manoel Abílio de Queiróz ${ }^{2}$; Maria Aldete J da F Ferreira ${ }^{3}$; Gláucia SC Buso ${ }^{3}$ \\ ${ }^{1}$ UFPE-Dep $^{\text {to. }}$ Genética, Av. Prof. Moraes Rego, 1235, 50670-901 Recife-PE; ${ }^{2}$ UNEB-Dep ${ }^{\text {to. }}$ Tecnologia e Ciências Sociais, Av. Edgard \\ Chastinet s/n ${ }^{\circ}$ São Geraldo, 48905-680 Juazeiro-BA; ${ }^{3}$ Embrapa Recursos Genéticos e Biotecnologia, C. Postal 02372, 70770-900 \\ Brasília-DF; E-mail: mlsluciene@yahoo.com.br; manoelabilio@terra.com.br; aldete@cenargen.embrapa.br; buso@cenargen.embrapa.br
}

\section{RESUMO}

Acessos de melancia do Banco de Germoplasma da Embrapa Semi-Árido, coletados a partir de sementes de polinização livre na Chapada Diamantina, em Irecê e em Vitória da Conquista, na Bahia, foram caracterizados através de descritores morfológicos e moleculares, adicionando-se ao grupo, como testemunha a cultivar Crimson Sweet. O experimento de campo, em blocos ao acaso com três repetições, foi conduzido na estação experimental da Embrapa Semi-Árido, em Petrolina-PE. Os dados obtidos foram submetidos à análise uni- e multivariada, com agrupamento pelo método de Tocher. Amostras de cinco a oito indivíduos de cada um dos 43 acessos avaliados, foram submetidas à análise molecular utilizando marcadores RAPD, obtidos através de seis primers. O polimorfismo revelado por estes marcadores foi utilizado para estimar os coeficientes de similaridade de Jaccard médios para cada acesso e realizar a análise de agrupamentos, também pelo método de Tocher. Foram encontradas diferenças significativas entre os acessos para todos os descritores morfológicos aplicados, exceto número de frutos por planta. Oito descritores morfológicos (comprimento do ramo principal, espessura da casca na região da inflorescência, padrão de listras dos frutos, teor de sólidos solúveis, formato dos frutos, cor externa dos frutos, espessura da casca na região distal e peso dos frutos) explicaram 79\% da variação entre acessos. Quando a testemunha, a cultivar Crimson Sweet foi incluída na análise multivariada, foram formados apenas dois grupos: um grupo com ela própria e, o outro, com todos os demais acesssos. Quando a testemunha foi excluída da análise, os acessos se distribuíram em nove grupos, sendo que um deles englobou $69 \%$ do total de acessos avaliados. Foram identificados 64 marcadores RAPD, sendo que 31 foram polimórficos. O agrupamento dos acessos com base na informação desses marcadores, utilizando o método de Tocher, resultou em 28 grupos, 24 deles com um único acesso. Nenhum dos grupos com mais de um acesso foi constituído por acessos provenientes da mesma região. Os marcadores RAPD revelaram polimorfismo expressivo em vários acessos, o que indica que estes marcadores podem ser utilizados na caracterização de acessos em Bancos de Germoplasma de melancia.

Palavras-chave: Citrullus lanatus, descritores morfológicos, marcadores moleculares, RAPD, germoplasma.

\section{ABSTRACT \\ Morphological and molecular characterization of watermelon}

Accessions from the Watermelon Germplasm Bank collected in three different regions of the state of Bahia were characterized using morphological and molecular descriptors. The cultivar Crimson Sweet was added to the group as a check genotype. The field trial was carried out at the Experimental Station of Embrapa, PetrolinaPE. Uni- and multivariate analyses were performed. Samples of five to eight individuals from each of the 43 accessions were analyzed by RAPD technique, using six primers. Jaccard mean similarity coefficients among accessions and grouping by Tocher method were estimated. There were significant differences among accessions for all descriptors, except for the number of fruits per plant. Eight morphological descriptors (length of the main stem and fruit stripe pattern, soluble solid content, shape, weight, external color, and rind thickness at the flower scar and at the distal region) retained $79 \%$ of the variation observed among accessions. When the multivariate analysis was performed including cultivar Crimson Sweet, only two groups were formed: a group with solely the cultivar itself, and another with all the other accessions. When the cultivar Crimson Sweet was not included, the multivariate analysis showed nine groups of accessions, with a single group containing $69 \%$ of the accessions. Sixty-four RAPD markers were identified, out of which 31 were polymorphic. When accessions were grouped based on this molecular information, 28 groups were formed, 24 of them with a single accession. None of the groups with more than one accession contained individuals with the same geographical origin. RAPD markers revealed expressive polymorphism in several accessions, which is a good indication that such class of markers could be used in the characterization of accessions in watermelon germplasm banks.

Keywords: Citrullus lanatus, morphological descriptors, molecular markers, RAPD, germplasm.

\section{(Recebido para publicação em 25 de julho de 2005; aceito em 20 de dezembro de 2006)}

\begin{abstract}
A melancia, embora não sendo brasileira, tem se destacado entre as principais olerícolas cultivadas no país. A expectativa de mercado para 2007 é que a produção brasileira fique em torno de 920 mil toneladas, participando expressivamente no volume total de hor-
\end{abstract}

taliças produzidas no Brasil (MAPA, 2006).

Como recurso genético, a melancia encontra-se representada no Banco Ativo de Germoplasma (BAG) de Cucurbitáceas para o Nordeste brasileiro, localizado na Embrapa Semi-Árido, em Petrolina-PE. Este banco de germoplasma foi formado na década de 90 a partir de coletas de sementes e frutos provenientes da agricultura tradicional em diferentes regiões do Nordeste brasileiro. Atualmente, o BAG é composto por aproximadamente 600 aces- 
sos de melancia, preservados na forma de sementes mantidas em câmara fria a $10^{\circ} \mathrm{C}$ e $40 \%$ de umidade relativa, com multiplicação a campo (Queiróz, 1998).

Os trabalhos de caracterização podem contribuir para identificação de possíveis duplicatas e fornecer dados que facilitem a organização dos acessos em bancos de germoplasma (Ritschel et al., 1999). A descrição da diversidade genética de acessos de melancia do BAG de Cucurbitáceas da Embrapa Semi-Árido tem sido normalmente realizada a partir da caracterização morfológica (Romão, 1995). Contudo, efeitos ambientais podem influenciar na expressão dos caracteres, alterando a sua eficácia. Por esta razão, marcadores moleculares podem ser aplicados para auxiliar na caracterização de acessos mantidos em bancos de germoplasma. Por produzirem informações ao nível de DNA, os marcadores moleculares revelam o polimorfismo de um gene expresso ou de um segmento específico do DNA, eliminando possíveis interferências ambientais (Ferreira \& Grattapaglia, 1996). Dentre os diferentes marcadores, o baixo custo, a rapidez na obtenção dos dados e a necessidade de pouca quantidade de DNA têm contribuído para a ampla utilização de marcadores do tipo RAPD (Random Amplified Polymorphism of DNA). Esta técnica é baseada na PCR (Polymerase Chain Reaction) e utiliza um único primer para dirigir a reação.

Capeloto (2003) aplicou a técnica RAPD na caracterização molecular de dezoito acessos de melancia do BAG de Cucurbitáceas da Embrapa Semi-Árido, sendo dezesseis coletados na Ilha de São Luís e dois nos municípios de Itapicuru e Barra do Corda, todos localizados no Maranhão. Os acessos mais divergentes foram coletados na Ilha de São Luís, enquanto os acessos coletados em Itapicuru e Barra do Corda apresentaram alta similaridade com os demais acessos, indicando que na amostra analisada a diversidade genética não estava associada a origens geográficas distintas. Porém, Capeloto (2003) não procedeu a uma caracterização morfológica dos mesmos acessos, o que permitiria não só a comparação entre os dois sistemas de caracterização para germoplasma de melancia, mas também a identificação de descritores fenotípicos com contribuição para a divergência genética entre acessos coletados nesta região.

Assim sendo, este trabalho teve por objetivo descrever morfológica e molecularmente, por meio da técnica de RAPD, acessos de melancia coletados em três regiões do estado da Bahia, para examinar a diversidade genética revelada entre os mesmos através de sistemas distintos de caracterização de germoplasma.

\section{MATERIAL E MÉTODOS}

Foram caracterizados 42 acessos de melancia do Banco Ativo de Cucurbitáceas da Embrapa Semi-Árido, coletados na forma de sementes de polinização livre, em três regiões distintas do estado da Bahia: Chapada Diamantina (acessos de 1 a 13), Irecê (14 a 28) e Vitória da Conquista (29 a 42). As três regiões são relativamente afastadas entre si, o que nos permitiria esperar que as sementes dos agricultores estivessem isoladas, exceto por ações de permuta que ocorrem entre produtores das mais variadas regiões (Romão, 1995). Como testemunha utilizou-se a cultivar Crimson Sweet.

O experimento de campo foi conduzido no Campo Experimental de Bebedouro em Petrolina-PE, em delineamento de blocos ao acaso, com três repetições e parcelas constituídas por seis plantas. O espaçamento utilizado foi de $3,0 \times 0,8 \mathrm{~m}$, sendo avaliadas, individualmente, as três plantas centrais de cada parcela. A irrigação foi feita em sulcos de infiltração e os tratos culturais e fitossanitários foram os mesmos utilizados rotineiramente para cultivo da melancia.

Foram utilizados dezessete descritores morfológicos: comprimento do ramo principal (CP, em $\mathrm{m})$; diâmetro do ramo principal (DR, em cm); número de ramos (NR); produção por planta (PP, em kg); número de frutos por planta (NF); peso do fruto (PF, kg); diâmetro transversal do fruto (DT, em cm); diâmetro longitudinal do fruto (DL, em $\mathrm{cm})$; formato do fruto (FF), correspondendo a um índice proveniente da divisão do diâmetro transversal pelo diâmetro longitudinal, sendo que os frutos com relação menor do que 0,5 foram considerados longos, aqueles com a relação entre diâmetros ao redor de 1,0 foram considerados redondos e aqueles com valores entre 0,5 e 1,0 foram considerados intermediários; espessura da casca na região do pedúnculo (ECP, em $\mathrm{cm}$ ); da inflorescência (ECI, em cm); da região distal $(\mathrm{ECD}$, em $\mathrm{cm}$ ) e proximal do solo (ECS, em cm); cor da polpa (CP) conforme a escala de notas, sendo $1=$ vermelha, $2=$ rosa-intenso, $3=$ rosa-médio, $4=$ rosa-claro e $5=$ branca; cor externa do fruto $(\mathrm{CF})$, conforme escala de notas, sendo $1=$ verde-escuro, $2=$ verde-médio, $3=$ verde-claro e $4=$ amarelo; padrão de listras da casca do fruto (PL), conforme escala de notas, sendo $1=$ sem listras, $2=$ listra larga, 3= listra estreita e 4= mosqueado e; teor de sólidos solúveis (TS, em ${ }^{\circ}$ Brix).

Os dados obtidos foram submetidos à análise de variância. Foram estimadas as distâncias generalizadas de Mahalanobis $\left(D^{2}\right)$, ao passo que os grupos foram delimitados através do método de agrupamento de Tocher (Rao, 1952). Todas as análises foram efetuadas no programa GENES (Cruz, 2001).

Amostras de cinco a oito indivíduos de cada um dos 42 acessos e da cultivar Crimson Sweet foram descritas molecularmente através da técnica RAPD. Para extração do DNA foi empregado o protocolo de Ferreira \& Grattapaglia (1996). A quantificação do DNA foi realizada em géis de agarose $1 \%(\mathrm{p} / \mathrm{v})$, comparando visualmente a intensidade das bandas do DNA extraído com bandas do DNA do fago lambda com concentrações conhecidas (100 a $500 \mathrm{ng}$ ). Após a quantificação, o DNA foi diluído em uma concentração de 3 çg $\mu \mathrm{L}^{-1}$, para ser utilizado nas reações de amplificação. Nestas também foi utilizado o protocolo descrito por Ferreira \& Grattapaglia (1996), mas com alguns ajustes para otimizar a reação para melancia. As reações de amplificação do DNA foram realizadas com um coquetel de reagentes contendo $3,0 \mu \mathrm{L}$ de DNA genômico a $3 \mathrm{ng} \mu \mathrm{L}^{-1} ; 4,92 \mu \mathrm{L}$ de água milli-Q autoclavada; $1,30 \mu \mathrm{L}$ de tampão 10X para Taq DNA Polimerase; 1,04 $\mu \mathrm{L}$ de dNTP 2,5 mM; 1,04 $\mu \mathrm{L}$ de 
BSA 2,5 mM; $1,5 \mu \mathrm{L}$ de Primer (Operon Technologies, USA) $10 \mathrm{ng} \mu \mathrm{L}^{-1}$ e $0,2 \mu \mathrm{L}$ de enzima Taq DNA polimerase $\left(5 \mathrm{U}^{\mathrm{L}} \mathrm{L}^{-1}\right)$. Seis primers selecionados foram utilizados nas análises: OPF-02, OPF-16, OPO02, OPO-07, OPO-09, e OPB-14.

As reações de amplificação foram conduzidas em termociclador PTC-100 da MJ Research Inc. O programa foi iniciado com pré-desnaturação a $96^{\circ} \mathrm{C}$, por 1 minuto, seguida de 40 ciclos de 1 minuto a $92^{\circ} \mathrm{C}, 1$ minuto a $35^{\circ} \mathrm{C}$ e 2 minutos a $72^{\circ} \mathrm{C}$, com extensão final de 5 minutos a $72^{\circ} \mathrm{C}$. Os fragmentos amplificados foram separados por eletroforese em gel de agarose $1,5 \%(\mathrm{p} / \mathrm{v})$, usando tampão TBE pH 8,0 (0,09 M de Tris; 0,09 M de ácido bórico e $2 \mathrm{mM}$ de EDTA), a uma tensão constante de $3 \mathrm{~V}$ $\mathrm{cm}^{-1}$. Os géis foram corados com $10 \mathrm{~mL}$ de brometo de etídio $\left(10 \mathrm{mg} \mathrm{mL}^{-1}\right)$ diluídos em $100 \mathrm{~mL}$ de TBE e documentados sob luz ultravioleta. Foi utilizado padrão de peso molecular de $1 \mathrm{~kb}$ para identificar os fragmentos amplificados.

Como o RAPD é um marcador dominante, os fragmentos amplificados foram interpretados como presença (1) ou ausência (0) de bandas e utilizados para estimar as médias dos coeficientes de similaridade de Jaccard e proceder ao agrupamento pelo método de Tocher, empregando o programa GENES (Cruz, 2001). Com base na matriz gerada, foi calculada a porcentagem de locos polimórficos para cada acesso (quociente entre o número de bandas polimórficas e o total de bandas).

\section{RESULTADOS E DISCUSSÃO}

\section{Descritores morfológicos}

Os acessos avaliados apresentaram diferenças significativas entre si para todos os descritores utilizados, com exceção da característica número de frutos por planta (Tabela 1). Esses resultados evidenciam a existência de diversidade genética entre os 43 acessos avaliados. Houve variação aleatória pronunciada para alguns descritores, o que pode ser verificado pela magnitude dos coeficientes de variação (Tabela 1). Foram especialmente afetadas as características controladas por muitos genes e, por isso, mais sensíveis aos fatores

Tabela 1. Significância de quadrados médios e coeficiente e amplitude de variação de descritores morfológicos utilizados para caracterizar 43 acessos de melancia. Recife, UFPE, 2004.

\begin{tabular}{|c|c|c|c|c|}
\hline \multirow{2}{*}{ Características } & \multirow{2}{*}{$\begin{array}{c}\begin{array}{c}\text { Quadrados } \\
\text { médios }^{1}\end{array} \\
\text { Acessos } 42\end{array}$} & \multirow{2}{*}{$\begin{array}{c}\begin{array}{r}\text { Coeficiente } \\
\text { de Variação }\end{array} \\
(\%)\end{array}$} & \multicolumn{2}{|c|}{ Amplitude de variação } \\
\hline & & & $\begin{array}{l}\text { Menor } \\
\text { valor }\end{array}$ & Maior valor \\
\hline Comprimento do ramo & $3,265^{* *}$ & 15,6 & 2,59 & 8,12 \\
\hline Diâmetro do ramo & $0,057^{* *}$ & 14,7 & 0,73 & 1,86 \\
\hline Número de ramos & $4,676^{*}$ & 19,1 & 3,67 & 13,67 \\
\hline Produção por planta & $4,597^{* *}$ & 28,6 & 1,53 & 10,27 \\
\hline Número de frutos/planta & $0,312^{\text {ns }}$ & 28,1 & 1,00 & 4,00 \\
\hline Peso de fruto & $4,497^{* *}$ & 28,3 & 1,20 & 11,00 \\
\hline Diâmetro transversal do fruto & $50,04^{* *}$ & 14,5 & 13,27 & 34,33 \\
\hline Diâmetro longitudinal. do fruto & $8,75^{\star *}$ & 8,9 & 10,70 & 23,63 \\
\hline Formato do fruto & $0,058^{* *}$ & 14,6 & 0,43 & 1,02 \\
\hline Espessura da casca ${ }^{1}$ & $0,665^{*}$ & 35,7 & 0,67 & 3,62 \\
\hline Espessura da casca ${ }^{2}$ & $0,228^{* *}$ & 25,2 & 0,27 & 2,99 \\
\hline Espessura da casca ${ }^{3}$ & $0,131^{* *}$ & 20,6 & 0,53 & 1,87 \\
\hline Espessura da casca ${ }^{4}$ & $0,138^{* *}$ & 20,8 & 0,60 & 2,07 \\
\hline Cor da polpa & $1,055^{* *}$ & 11,5 & 1,00 & 5,00 \\
\hline Cor externa do fruto & $0,504^{* *}$ & 18,0 & 1,00 & 3,30 \\
\hline Padrão de listras & 0,870 ** & 27,3 & 1,00 & 4,00 \\
\hline Teor sólidos solúveis & $2,438^{* *}$ & 9,7 & 3,73 & 11,13 \\
\hline
\end{tabular}

$1 * * *$ = significativo a 1 e $5 \%$ de probabilidade, pelo teste de $\mathrm{F}, \mathrm{ns}=$ não-significativo; espessura da casca nas regiões: 1 - pedúnculo, 2- inflorescência, 3- distal e 4 - próxima do solo.

ambientais (Allard, 1971) como, por exemplo, a produção por planta e seus componentes (peso e número de frutos).

Alguns descritores morfológicos que apresentaram variação significativa entre os acessos são também importantes características agronômicas. Nestes casos, a existência de variação indica a possibilidade da utilização do banco de germoplasma para obtenção de ganhos no melhoramento da melancia. É o caso do comprimento do ramo principal. Esse caráter é importante porque determina o espaçamento entre plantas em cultivos comerciais. No que tange aos descritores do fruto, também muito importantes no desenvolvimento de novas cultivares, observou-se que houve uma variação acentuada para formato, cor externa, cor da polpa e teor de sólidos solúveis (Tabela 1).

O formato do fruto, estabelecido a partir da relação entre o diâmetro e o comprimento, foi predominantemente intermediário (relação entre 0,5 e 1,0), seguido pelos frutos considerados esféricos (relação ao redor de 1,00). Apenas três acessos apresentaram frutos considerados longos (relação abaixo de 0,5). Os frutos intermediários e esféricos apresentam maior porção de polpa co- mestível. Já o formato esférico poderá apresentar vantagens para acomodação em caixas, principalmente no caso de frutos pequenos. Entretanto, frutos esféricos têm maior tendência a apresentarem ocamento da polpa (Mohr, 1986). A variabilidade encontrada em relação ao formato de fruto foi semelhante àquela descrita por Queiroz et al. (2001) para acessos coletados em Irecê-BA e Pastos Bons-MA.

Os acessos de melancia apresentaram diversas tonalidades para cor da polpa, variando de branca a rósea e mostrando uma variação comparável àquelas estudadas por Romão (1995) e Queiroz et al. (2001). A cor da polpa é determinada por poucos genes, sendo a cor vermelha dominante sobre a amarela, porém, recessiva em relação à cor branca (Mohr, 1986), embora deva existir genes modificadores, uma vez que se encontram gradações nas tonalidades de cor encontradas. De fato, Ferreira (1996) encontrou variância genética aditiva para cor de polpa, indicando que a seleção recorrente poderá melhorar esse caráter.

Dois acessos apresentaram frutos de cor externa do mesmo padrão da culti- 
Tabela 2. Agrupamento de 42 acessos de melancia pelo método de otimização de Tocher a partir de descritores morfológicos, sem a cultivar Crimson Sweet. Recife, 2004

\begin{tabular}{ll}
\hline Grupos & Acessos \\
\hline \multicolumn{3}{l}{} & $3,5,7,8,9,11,12,13,14,15,16$ \\
I & $20,25,26,28,29,30,31,32,33$, \\
& 34,35 \\
& $36,37,38,39,40,41,42$ \\
II & $1,4,6$ \\
III & $18,22,23,27$ \\
IV & 4 \\
V & 21 \\
VI & 17 \\
VII & 2 \\
VIII & 28 \\
IX & 10 \\
\hline
\end{tabular}

var Crimson Sweet. Os demais acessos apresentaram cor externa variando de verde-claro ao verde-escuro. Vale salientar que o tipo 'Crimson Sweet' é a cor predominante comercialmente no país. No entanto, a característica de fruto mais significativa comercialmente é o teor de açúcar, indicado pelo teor de sólidos solúveis totais, que para a melancia varia de 11 a $13^{\circ}$ Brix nas cultivares mais comercializadas. Neste trabalho o teor de sólidos solúveis totais variou de 5 a $7,3^{\circ}$ Brix, atingindo valores mais altos que aqueles observados por Romão (1995) e semelhantes aos valores encontrados por Queiroz et al. (2001).

O agrupamento dos acessos utilizando as distâncias generalizadas de Mahalanobis $\left(D^{2}\right)$ obtidas a partir dos descritores morfológicos produziu tão somente dois conjuntos de acessos: um composto somente pela cultivar Crimson Sweet e, outro, composto por todos os demais acessos. Entretanto, quando os valores de $D^{2}$ foram obtidos sem incluir a cultivar Crimson Sweet foram formados nove grupos. O grupo I incluiu 29 dos 42 acessos avaliados, contando com acessos oriundos das três regiões da Bahia. Nos grupos II e III ficaram reunidos, respectivamente, três e quatro acessos. Porém, ao contrário do grupo I, os grupos II e III foram formados por acessos provenientes exclusivamente de uma mesma região, respectivamente a Chapada Diamantina e o município de Irecê. Os demais grupos foram formados por acessos isolados (Tabela 2).
A caracterização morfológica possibilita a identificação de descritores que possam ser utilizados na discriminação de acessos. Para atingir este fim, Singh (1981) propôs que os descritores fossem selecionados com base na contribuição relativa dos mesmos para a divergência. $\mathrm{O}$ descritor comprimento do ramo principal contribuiu com $14,2 \%$ da divergência entre os acessos, enquanto sete descritores relativos ao fruto (espessura da casca na região de inflorescência= $13,2 \%$; padrão de listras dos frutos= 10,2\%; teor de sólidos solúveis $=9,5 \%$; formato dos frutos $=9,4 \%$; cor externa dos frutos $=8,1 \%$; espessura da casca na região distal $=7,1 \%$ e peso dos frutos $=$ $7,0 \%$ ) contribuíram com $64,5 \%$ para a divergência. No total, estes oitos descritores explicaram $79 \%$ da divergência entre os acessos.

Romão (1995), também trabalhando com melancia, utilizou dezessete descritores quantitativos, que foram analisados por variáveis canônicas. Entre todos os descritores, nove explicaram $67 \%$ da variação entre acessos. Destes nove descritores, cinco (diâmetro e comprimento do fruto, peso do fruto, espessura da casca e teor de sólidos solúveis) apresentaram bom poder de discriminação também no presente estudo. Estes descritores, mesmo sensíveis a variações ambientais (Allard, 1971) apresentaram repetibilidade e devem ser levados em consideração nos trabalhos de caracterização de acessos de melancia.

\section{Caracterização molecular}

Foram identificados 64 marcadores RAPD, sendo 31 informativos. O agrupamento pelo método de Tocher com base nesses marcadores distribuiu os acessos em 28 grupos. O grupo I foi constituído por $25,6 \%$ dos acessos, sendo quatro acessos originários da Chapada Diamantina, dois de Irecê e cinco de Vitória da Conquista. O grupo II foi formado por dois acessos, um da Chapada Diamantina e outro de Vitória da Conquista; o grupo III, por três acessos, um de cada local de coleta e, o grupo IV, por dois acessos, um da Chapada Diamantina e outro de Vitória da Conquista. Os 24 grupos restantes foram formados por acessos únicos, incluindo a cultivar Crimson Sweet.

De acordo com Romão (1995), existe uma forte troca de sementes entre agricultores. Além disso, a agricultura tradicional do Nordeste brasileiro é um continuum. Esses dois fatores favorecem o aparecimento de tipos de plantas semelhantes, neste caso, melancias, entre acessos coletados em regiões diferentes. Vale salientar que a polinização da melancia é realizada por insetos, preferencialmente abelhas da espécie Apis mellifera, o que também favorece o transporte de pólen entre roças (Hodges \& Baxendale, 1995). Contudo, a seleção praticada pelos agricultores tende a fixar tipos distintos em determinadas regiões, o que pode explicar o aparecimento de grupos específicos, muitas vezes formados por um único acesso, como observado tanto nas análises morfológicas como moleculares.

Considerando que a matriz para análise dos dados morfológicos (Mahalanobis) é conceitualmente diferente da matriz molecular (coeficiente de Jaccard), não é apropriado comparar os métodos no que tange ao poder de discriminação entre acessos. Contudo, observa-se que o polimorfismo molecular encontrado em diversos acessos foi expressivo, chegando a alguns casos a $60 \%$, mesmo só tendo sido utilizados seis primers.

O RAPD é um marcador que tem sido amplamente utilizado em pesquisa de genética de plantas, inclusive de melancia, devido a sua facilidade de execução (Levi et al., 2002; Ferreira, 2000; Capeloto, 2003). Embora exista relato sobre a falta de reproducibilidade deste marcador (Jones et al., 1997), alguns primers (OP02, OP07, OP09, OPB14, por exemplo, todos empregados no presente trabalho) utilizados em pesquisas com marcadores moleculares em melancia apresentaram uma razoável reproducibilidade, permitindo a identificação de bandas consistentemente polimórficas (Levi et al., 2001; Capeloto, 2003; Silva, 2004). Contudo, é interessante notar que em alguns outros estudos, também utilizando marcadores RAPD em melancia, não foi encontrado polimorfismo (Hashizume et al., 1996; Lee et al., 1996; Zhang et al., 1993).

\section{AGRADECIMENTOS}

A primeira autora agradece ao Conselho Nacional de Pesquisa (CNPq) pela bolsa para finalização do curso de 
mestrado, às Professoras Dra. Ana Maria Benko-Iseppon, coordenadora do curso de Mestrado em Genética da UFPE em 2002 e Dra. Luiza Suely Semen Martins, pelo apoio e sugestões. Os dois primeiros autores agradecem à Embrapa Semi-Árido e à Embrapa Recursos Genéticos e Biotecnologia pelo apoio para realização dos trabalhos de campo e de laboratório.

\section{REFERÊNCIAS}

ALLARD RW. 1971. Princípios do melhoramento de plantas. New York: John Willey. 331p.

CAPELOTO A. 2003.Caracterização molecular entre e dentro de acessos de melancia através de RAPD-PCR. Jaboticabal: UNESP-FCAV. 62p. (Tese mestrado)

CRUZ CD. 2001. Programa Genes: aplicativo computacional em genética e estatística. Viçosa: UFV. 648p.

FERREIRA MAJF. 1996. Análise dialélica em melancia [Citrullus lanatus (Thunb.) Mansf.] Jaboticabal: UNESP-FCAV. 83p (Tese mestrado)

FERREIRA MAJF. 2000. Sistema reprodutivo $e$ potencial para o melhoramento genético de uma população de melancia [Citrullus lanatus (Thunb.) Matsum \& Nakai]. Piracicaba: USPESALQ. 105p (Tese doutorado)

FERREIRA ME; GRATTAPAGLIA D. 1996. Introdução ao uso de marcadores moleculares em análise genética. Brasília: EMBRAPACENARGEN. 220p.
HASHIZUME T; SHIMAMOTO I; HARUSHIMAY YUIM; SATO T; IMAI T; HIRAI M. 1996. Construction of a linkage map for watermelon [Citrullus lanatus (Thunb.) Matsum \& Nakai] using random amplified polymorphic DNA (RAPD). Euphytica 9: 265273

HODGES L; BAXENDALE F. 1995. Bee pollination of cucurbit crops. Horticulture. Disponível em http://www.ianrpubs.unl.edu/ horticulture/nf50.html. Acessado em julho de 1995.

JONES CJ; EDWARDS KJ; CASTAGLIONE S; WINFIELD MO; SALA F; van de WIEL C; BREDEMEIJER G; VOSMAN B; MATTHES M; DALY A; BRETSCHNEIDER R BETTINI P; BUIATTI M; MAESTRI E; MALCEVSCHI A; MARMIROLI N; AERT A; VOLCKAERT G; RUEDA J; LINACERO R; VAZQUEZ A; KARP A. 1997. Reproducibility testing of RAPD, AFLP, and SSR markers in plants by a network of European laboratories. Molecular Breeding 3: 381-390.

LEE SJ; SHIN JS; PARK KW; HONG YP. 1996. Detection of genetic diversity using RAPDPCR and sugar analysis in watermelon [Citrullus lanatus (Thunb.) Mansf.] germplasm. Theoretical and Applied Genetics 9: 719-725

LEVI A; THOMAS CE; WEHNER TC; ZHANG X. 2002. Low genetic diversity indicates the need to broaden the genetic base of cultivated watermelon. Hortscience 36:1096-1101

MAPA-Ministério da Agricultura, Pecuária e Abastecimento. 2006, 6 de dezembro. Disponível em http://www.agricultura.gov.br.
MOHR HC. 1986. Watermelon breeding. In: BASSET ML. (ed) (Breeding vegetables crops). Connecticut: USA: AVI Publishing Company. p. 37-66.

QUEIRÓZ MA. 1998. Cucurbitáceas no semi-árido do Nordeste brasileiro: resgate, conservação e uso. In: ENCONTRO SOBRE TEMAS DE GENÉTICA E MELHORAMENTO, 15. Anais... Piracicaba: ESALQ - Departamento de Genética. p.1-12.

QUEIROZ MA; ROMÃO RL; ASSIS JGA. 2001. Avaliação botânico-agronômica de acessos de melancia (Citrullus lanatus) coletados nas regiões de Irecê-Ba e Pastos Bons, MA. Sitientibus-Série Ciências Biológicas 1: 79-83.

RAO RC. 1952. Advance statistical in biometric research. New York: J. Wiley. 390p.

RITSCHEL PS; THOMAZELLI LC; HUAMÁN Z. 1999. Caracterização morfológica do germoplasma de batata-doce mantido pela EPAGRI. Brasília: EMBRAPA-CNPH. 7p.

ROMÃO RL. 1995. Dinâmica evolutiva e variabilidade de populações de melancia [Citrullus lanatus (Thunb.) Matsum \& Nakai] em três regiões do Nordeste brasileiro. Piracicaba: USP-ESALQ. 75p.

SILVA ML. 2004. Caracterização morfológica e molecular de acessos de melancia [Citrullus lanatus (Thunb.) Matsum \& Nakai). Recife: UFPE. 70p. (Tese mestrado)

SINGH D. 1981. The relative importance of characters affecting genetic divergence. Indian Journal of Genetics and Plant Breeding 41: 237-245

ZHANG XP; RHODES BB; KORUPSKA HS. 1993. RAPD molecular markers in watermelon. Cucurbit Genetic Cooperation Report 17:116-119 